\title{
Collective Action and Effective Dialogue to Address Gender Bias in Medicine
}

\author{
Jessica M Gold, MD, MS, ${ }^{1}$ Jessica M Allan, MD, ${ }^{2}$ Shawn L Ralston, MD, MA, MS, ${ }^{3}$ \\ $\mathrm{H}$ Barrett Fromme, MD, MHPE, ${ }^{4}$ Arti D Desai, MD, MSPH ${ }^{5}$
}

\begin{abstract}
'Stanford University School of Medicine and Lucile Packard Children's Hospital Stanford, Palo Alto, California; ${ }^{2}$ Palo Alto Medical Foundation and Lucile Packard Children's Hospital Stanford, Palo Alto, California; ${ }^{3} J o h n s$ Hopkins Children's Center, Baltimore, Maryland; ${ }^{4}$ University of Chicago, Pritzker School of Medicine, Chicago, Illinois; ${ }^{5}$ University of Washington, Seattle Children's Research Institute, Seattle, Washington.
\end{abstract}

n 2016, Pediatric Hospital Medicine (PHM) was recognized as a subspecialty under the American Board of Pediatrics (ABP), one of 24 certifying boards of the American Board of Medical Specialties. As with all new ABP subspecialty certification processes, a "practice pathway" with specific eligibility criteria allows individuals with expertise and sufficient practice experience within the discipline to take the certification examination. For PHM, certification via the practice pathway is permissible for the 2019, 2021, and 2023 certifying examinations. ${ }^{1}$ In this perspective, we provide an illustration of ABP leadership and the PHM community partnering to mitigate unintentional gender bias that surfaced after the practice pathway eligibility criteria were implemented. We also provide recommendations to revise these criteria to eliminate future gender bias and promote equity in medicine.

In July 2019, individuals within the PHM community began to share stories of being denied eligibility to sit for the 2019 exam. ${ }^{2}$ Some of the reported denials were due to an eligibility criterion related to "practice interruptions", which stated that practice interruptions cannot exceed three months in the preceding four years or six months in the preceding five years. Notably, some women reported that their applications were denied because of practice interruptions due to maternity leave. These stories raised significant concerns of gender bias in the board certification process and sparked collective action to revise the board certification eligibility criteria. A petition was circulated within the PHM community and received 1,479 signatures in two weeks.

Given the magnitude of concern, leaders within the PHM community, with support from the American Academy of Pediatrics, collaboratively engaged with the ABP and members of the ABP PHM subboard to improve the transparency and equity of the eligibility process. As a result of this activism and effective dialogue, the $\mathrm{ABP}$ revised the PHM board certification eligibility criteria and removed the practice interruption criterion. ${ }^{1}$ Through this unique experience of advocacy and partnership in medicine, the PHM community and ABP were able to work together to mitigate unintentional gender bias

Corresponding Author: Jessica Gold, MD, MS; E-mail: jgold2@stanford.edu; Telephone: 650-736-4423

Received: September 17, 2019; Revised: September 19, 2019;

Accepted: September 20, 2019

๑ 2019 Society of Hospital Medicine DOI 10.12788/jhm.3331 in the board certification process. However, this collaboration must continue as we believe the revised criteria remain unintentionally biased against women.

Gender bias is defined as the unfair difference in the way men and women are treated. ${ }^{3}$ Maternal bias is further characterized as bias experienced by mothers related to motherhood, often involving discrimination based on pregnancy, maternity leave, or breastfeeding. Both are common in medicine. Two-thirds of physician mothers report experiencing gender bias and more than a third experience maternal bias. ${ }^{4}$ This bias may be explicit, or intentional, but often the bias is unintentional. This bias can occur even with equal representation of women and men on committees determining eligibility, and even when the committee believes it is not biased. ${ }^{5}$ Furthermore, gender or maternal bias negatively affects individuals in medicine in regards to future employment, career advancement, and compensation. ${ }^{6-11}$

Given these implications, we celebrate the removal of the practice interruptions criterion as it was unintentionally biased against women. Eligibility criteria that considered practice interruptions would have disproportionately affected women due to leaves related to pregnancy and due to discrepancies in the length of parental leave for mothers versus fathers. Though the ABP's initial review of cases of denial did not demonstrate a significant difference in the proportion of men and women who were denied, these data may be misleading. Potential reasons why the ABP did not find significant differences in denial rates between women and men include: (1) some women who had recent maternity leaves chose not to apply because of concerns they may be denied; or (2) some women did not disclose maternity leaves on their application because they did not interpret maternity leave to be a practice interruption. This "self-censoring" may have resulted in incomplete data, making it difficult to fully understand the differential impact of this criterion on women versus men. Therefore, it is essential that we as a profession continue to identify any areas where gender bias exists in determining eligibility for certification, employment, or career advancement within medicine and eliminate it.

Despite the improvements made in the revised criteria, further revision is necessary to remove the criterion related to the "start date", which will differentially affect women. This criterion states that an individual must have started their PHM practice on or before July of the first year of a four-year look-back period (eg, July 2015 for the 2019 cycle). We present three the- 


\section{TABLE. Theoretical Cases to Illustrate Gender Bias in the Pediatric Hospital Medicine Board Certification Eligibility Criteria}

\begin{tabular}{|c|c|c|c|}
\hline Applicant & Context & Applicant-Reported Hours & Eligibility Determination \\
\hline 1 & $\begin{array}{l}\text { Full-time in PHM practice for } 4 \text { years from July 1, } 2015 \\
\text { to June 30, 2019. This individual had a 6-month practice } \\
\text { interruption from January 1, } 2015 \text { to June 30, } 2015 \text {. }\end{array}$ & $\begin{array}{l}\text { Spent } 1,000 \text { work hours in the direct care of hospitalized } \\
\text { children in the first year and 2,000 work hours in each of } \\
\text { the subsequent three years, resulting in 7,000 direct patient } \\
\text { care hours. }\end{array}$ & Would be eligible under the revised practice pathway criteria. \\
\hline 2 & $\begin{array}{l}\text { Full-time in PHM practice for almost } 4 \text { years from October } \\
1,2015 \text { to June } 30,2019 \text {. This individual started her PHM } \\
\text { practice } 12 \text { weeks into the "look-back" period due to the } \\
\text { birth of her child in July } 2015 \text {. }\end{array}$ & $\begin{array}{l}\text { Spent } 1,500 \text { work hours in the direct care of hospitalized } \\
\text { children in the first year and } 2,000 \text { work hours in each of } \\
\text { the subsequent three years, resulting in 7,500 direct patient } \\
\text { care hours. }\end{array}$ & $\begin{array}{l}\text { Would be ineligible in } 2019 \text { under the revised practice } \\
\text { pathway criteria (solely based on the start date criteriona), } \\
\text { but may be eligible in } 2021 \text {. }\end{array}$ \\
\hline 3 & $\begin{array}{l}\text { Plans to practice full-time in PHM practice for almost } 4 \\
\text { years from August 1, } 2019 \text { to June } 30,2023 \text {. This individual } \\
\text { delayed the start of her PHM practice by } 4 \text { weeks due to a } \\
\text { maternity leave during residency that delayed her residency } \\
\text { graduation date. }\end{array}$ & $\begin{array}{l}\text { Will spend 1,833 work hours in the direct care of } \\
\text { hospitalized children in the first year and 2,000 work hours } \\
\text { in each of the subsequent three years, resulting in } 7,833 \\
\text { direct patient care hours. }\end{array}$ & $\begin{array}{l}\text { Will be ineligible for the } 2023 \text { exam and the practice pathway } \\
\text { (solely based on the July start-date criterion })^{\text {) }} \text {, as } 2023 \text { is the } \\
\text { final year the exam will be offered under the practice pathway. }\end{array}$ \\
\hline
\end{tabular}

a This criterion states that an individual must have started their PHM practice on or before July of the first year of the four-year look-back period (eg, July 2019 for the 2023 cycle).

Abbreviation: PHM, pediatric hospital medicine.

oretical cases to illustrate gender bias with respect to this criterion (Table). Even though Applicants \#2 and \#3 accrue far more than the minimum number of hours in their first year-and more hours overall than Applicant \#1-both of these women will remain ineligible under the revised criteria. While Applicant \#2 could be eligible for the 2021 or 2023 cycle, Applicant \#3, who is new to PHM practice in 2019 as a residency graduate, will not be eligible at all under the practice pathway due to delayed graduation from residency.

Parental leave during residency following birth of a child may result in the need to make up the time missed. ${ }^{12}$ This means that more women than men will experience delayed entry into the workforce due to late graduation from residency. ${ }^{13}$ Women who experience a gap in employment at the start of their PHM practice due to pregnancy or childbirth will also be differentially affected by this criterion. If this same type of gap were to occur later in the year, it would no longer impact a woman's eligibility under the revised criteria. Therefore, we implore the $\mathrm{ABP}$ to reevaluate this criterion which results in a hidden "practice interruption" penalty. Removing eligibility criteria related to practice interruptions, wherever they may occur, will not only eliminate systematic bias against women, but may also encourage men to take paternity leave, for which the benefits to both men and women are well described. ${ }^{14,15}$

We support the ABP's mission to maintain the public's trust by ensuring PHM board certification is an indicator that individuals have met a high standard. We acknowledge that the $\mathrm{ABP}$ and PHM subboard had to draw a line to create minimum standards. The start date and four-year look-back criteria were informed by prior certification processes, and the PHM community was given the opportunity to comment on these criteria prior to final ABP approval. However, now that we have become aware of how the start date criteria can differentially impact women and men, we must reevaluate this line to ensure that women and men are treated equally. Similar to the removal of the practice interruptions criterion, we do not believe that removal of the start date criterion will in any way compromise these standards. A four-year look-back period will still be in place and individuals will still be required to accrue the minimum number of hours in the first year and each subsequent year of the four-year period.

Despite any change in the criteria, there will be individuals who remain ineligible for PHM board certification. We will need to rely on institutions and the societies that lead PHM to remember that not all individuals had the opportunity to certify as a pediatric hospitalist, and for some, this was due to maternity leave. No woman should have to worry about her future employment when considering motherhood.

We hope the lessons learned from this experience will be informative for other specialties considering a new certification. Committees designing new criteria should have proportional representation of women and men, inclusion of underrepresented minorities, and members with a range of ages, orientations, identities, and abilities. Criteria should be closely scrutinized to evaluate if a single group of people is more likely to be excluded. All application reviewers should undergo training in identifying implicit bias. ${ }^{16}$ Once eligibility criteria are determined, they should be transparent to all applicants, consistently applied, and decisions to applicants should clearly state which criteria were or were not met. Regular audits should be conducted to identify any bias. Finally, transparent and respectful dialogue between the certifying board and the physician community is paramount to ensuring continuous quality improvement in the process.

The PHM experience with this new board certification process highlights the positive impact that the PHM community had engaging with the ABP leadership, who listened to the concerns and revised the eligibility criteria. We are optimistic that this productive relationship will continue to eliminate any gender bias in the board certification process. In turn, PHM and the $\mathrm{ABP}$ can be leaders in ending gender inequity in medicine.

Disclosures: The authors have nothing to disclose. 


\section{References}

1. Nichols DG, Woods SK. The American Board of Pediatrics response to the Pediatric Hospital Medicine petition. J Hosp Med. 2019;14(10):586-588. https://doi.org/10.12788/jhm.3322

2. Don't make me choose between motherhood and my career. https://www. kevinmd.com/blog/2019/08/dont-make-me-choose-between-motherhoodand-my-career.html. Accessed September 16, 2019.

3. GENDER BIAS | definition in the Cambridge English Dictionary. April 2019. https://dictionary.cambridge.org/us/dictionary/english/gender-bias.

4. Adesoye T, Mangurian C, Choo EK, Girgis C, Sabry-Elnaggar H, Linos E. Perceived discrimination experienced by physician mothers and desired workplace changes: A cross-sectional survey. JAMA Intern Med. 2017;177(7):10331036. https://doi.org/10.1001/jamainternmed.2017.1394

5. Régner I, Thinus-Blanc C, Netter A, Schmader T, Huguet P. Committees with implicit biases promote fewer women when they do not believe gender bias exists. Nat Hum Behav. 2019. https://doi.org/10.1038/s41562-019-0686-3

6. Trix F, Psenka C. Exploring the color of glass: Letters of recommendation for female and male medical faculty. Discourse Soc. 2003;14(2):191-220. https:// doi.org/10.1177/0957926503014002277

7. Correll SJ, Benard S, Paik I. Getting a job: Is there a motherhood penalty? Am J Sociol. 2007;112(5):1297-1339. https://doi.org/10.1086/511799

8. Aamc. Analysis in Brief - August 2009: Unconscious Bias in Faculty and Leadership Recruitment: A Literature Review; 2009. https://implicit.harvard.edu/. Accessed September 10, 2019.

9. Wright $A L$, Schwindt $L A$, Bassford $T L$, et al. Gender differences in academic advancement: patterns, causes, and potential solutions in one US College of Medicine. Acad Med. 2003;78(5):500-508. https://doi.org/10.1097/00001888200305000-00015

10. Weaver AC, Wetterneck TB, Whelan CT, Hinami K. A matter of priorities? Exploring the persistent gender pay gap in hospital medicine. $\mathrm{J}$ Hosp Med. 2015;10(8):486-490. https://doi.org/10.1002/jhm.2400

11. Frintner MP, Sisk B, Byrne BJ, Freed GL, Starmer AJ, Olson LM. Gender differences in earnings of early- and midcareer pediatricians. Pediatrics. September 2019:e20183955. https://doi.org/10.1542/peds.2018-3955

12. Section on Medical Students, Residents and Fellowship Trainees, Committee on Early Childhood. Parental leave for residents and pediatric training programs. Pediatrics. 2013;131(2):387-390. https://doi.org/10.1542/peds.2012-3542

13. Jagsi R, Tarbell NJ, Weinstein DF. Becoming a doctor, starting a family - leaves of absence from graduate medical education. N Engl J Med. 2007;357(19):1889-1891. https://doi.org/10.1056/NEJMp078163

14. Nepomnyaschy $L$, Waldfogel J. Paternity leave and fathers' involvement with their young children. Community Work Fam. 2007;10(4):427-453. https://doi. org/10.1080/13668800701575077

15. Andersen SH. Paternity leave and the motherhood penalty: New causal evidence. J Marriage Fam. 2018;80(5):1125-1143. https://doi.org/10.1111/ jomf.12507.

16. Girod S, Fassiotto M, Grewal D, et al. Reducing Implicit Gender Leadership Bias in Academic Medicine With an Educational Intervention. Acad Med. 2016;91(8):1143-1150. https://doi.org/10.1097/ACM.0000000000001099 